\title{
Clinopodium dolichodontum (P.H.Davis) Bräuchler \& Heubl 'un In vitro Çimlenmesi ve Fide Gelişimi Üzerine Araştırmalar
}

\author{
Yelda Emek ${ }^{1^{*}}$ \\ 1* Aydın Adnan Menderes Üniversitesi, Ziraat Fakültesi, Tarımsal Biyoteknoloji Bölümü, Aydın,Türkiye, (ORCID: 0000-0003-1095-3908), \\ velda@adu.edu.tr
}

(İlk Geliş Tarihi 11 Ekim 2021 ve Kabul Tarihi 6 Aralık 2021)

(DOI: 10.31590/ejosat.1007952)

ATIF/REFERENCE: Emek, Y. (2021). Clinopodium dolichodontum (P.H.Davis) Bräuchler \& Heubl 'un In vitro Çimlenmesi ve Fide Gelişimi Üzerine Araştırmalar. Avrupa Bilim ve Teknoloji Dergisi, (31), 469-474.

Öz

Labiatae familyasına ait Clinopodium dolichodontum (P.H.Davis) Bräuchler \& Heubl nesli tehdit altında olan endemik ve tıbbi öneme sahip bir türdür. $\mathrm{Bu}$ familyanın üyeleri sekonder metabolit ve antioksidan özellikleri ile karakterize edilmektedir. C. dolichodontum izomenton, cts-piperiton oksit, pulegon, piperiton içermektedir. Türün doğal populasyonunun küçük olması nedeniyle çoğaltılması için alternatif yönteme ihtiyaç duyulmaktadır.

Bu çalışmada, $C$. dolichodontum 'un in vitro çimlenmesi ve fide gelişimi araştırılmıştır. İlk olarak, in vitro çimlenme üzerine besin ortamlarının ve giberellik asidin etkisi araştırılmıştır. Sterilize edilen tohumlar, MS, B5 ve WH (White) sıvı ortamlarında kültüre alındı. Buna ilaveten, distile su (DS) kontrol olarak kullanılmıştır. DS ortamında diğer ortamlardan daha yüksek oranda çimlenme elde edilmiştir. Tohumların in vitro çimlenmesi üzerine giberellik asit $\left(\mathrm{GA}_{3}\right)$ 'in etkisini belirlemek için tohumlar $\mathrm{GA}_{3}$ ilaveli $(1,2$ veya 3 $\left.\mathrm{mg} \mathrm{L}^{-1}\right)$ DS'da kültüre alınmıştır. En yüksek çimlenme değeri (\% 80) $1 \mathrm{mgL}^{-1} \mathrm{GA}_{3}$ içeren ortamda elde edilmiştir.

İkinci olarak ise in vitro fide gelişimi için uyun besin ortamı araştırılmıştır. Çimlenme sonucunda elde edilen bitkicikler fide gelişimi için katılaştırılmış MS, WH ve B5 ortamlarına aktarılmışlardır. İkinci alt kültür sonunda fide gelişimi, sürgün sayısı, maksimum sürgün boyu, kök sayısı ve kök boyu dikkate alınarak değerlendirmiştir. Elde edilen bulgulara göre MS ortamı in vitro fide gelişimi için en uygun besin ortamı olarak belirlenmiştir.

Anahtar Kelimeler: Clinopodium dolichodontum, In vitro, Çimlenme, Gibberellik asit (GA 3 ), Fide gelişimi.

\section{Researchs on In vitro Germination and Seedling Devolopment of Clinopodium dolichodontum (P.H.Davis) Bräuchler \& Heubl}

\begin{abstract}
Clinopodium dolichodontum (P.H. Davis) Bräuchler \& Heubl, belonging to the Labiatae (Lamiaceae) family, is a critically endangered endemic and medicinal plant. Members of this family are characterized by their secondary metabolite and antioxidant properties. $C$. dolichodontum contains isomentone, cts-piperitone oxide, pulegon, piperitone. Due to the small natural population of the species, an alternative method is needed for the propagation of individuals of the species.

In this paper, in vitro germination and seedling growth of C.dolichodontum were investigated. At the first step, the effect of media and gibberellic acid on in vitro seed germination was investigated. The sterilised seeds were cultured on MS, B5 and WH (White) liquid media. Additionally, distilled water (DW) was used as a control. A higher ratio of germination was obtained on the DW medium than in other media. To determine the effect of gibberellic acid $\left(\mathrm{GA}_{3}\right)$ on in vitro germination, seeds were cultured on DW supplemented with $\mathrm{GA}_{3}\left(1,2\right.$ or $\left.3 \mathrm{mg} \mathrm{L}^{-1}\right)$. The highest germination value (80\%) was obtained on DW with $1 \mathrm{mg} \mathrm{L}^{-1} \mathrm{GA}_{3}$.

At the second step, an appropriate medium for in vitro seedling development was investigated. Plantlets obtained from germinated seeds were transferred to solidified MS, B5 and WH media for seedling development. After the end of two subcultures the development of seedlings was evaluated by taking into account the number of shoots, maximum shoot length, number of roots and root length. MS was determined the most suitable medium for seedling development according to findings.
\end{abstract}

Keywords: Clinopodium dolichodontum, In vitro, Germination, Gibberellic acid ( $\left.\mathrm{GA}_{3}\right)$, Seedling development

\footnotetext{
*Sorumlu Yazar: yelda@adu.edu.tr
} 


\section{Giriş}

Türkiye, yaklaşık 11.707 çiçekli bitki türü ile biyolojik çeşitlilik bakımından Dünya'nın en zengin ülkelerindendir. (Güner ve ark., 2000, Güner ve ark., 2012). Lamiaceae (Labiatae) bu zenginlik içerisinde yer alan 3. büyük familyadır. Aynı zamanda tür sayısı bakımından da gen merkezi durumundadır. $\mathrm{Bu}$ familya ülkemiz florasında 346 taksonu endemik olan 782 takson ve 48 genus ile temsil edilmektedir. Endemizim değeri \% 44.2 dir (Ertan ve ark., 2001; Arslan ve ark., 2002; Celep ve Dirmenci, 2017). Familyanın üyeleri içerdiği biyolojik bileşikler nedeniyle tıbbi olarak geniş bir kullanım alanına sahiptirler.

Tıbbi önem taşıyan bitkiler ilk çağlardan beri halk ilacı olarak yaygın kullanıma sahiptirler (Tosun ve ark., 2016). Floramızda yer alan bu türlerden ilaç, boya, baharat ve gida olarak yararlanılması köklü bir gelenek haline gelmiştir (Çelikol, 2015). $\mathrm{Bu}$ familya üyelerinin bir kısmı geniş yayılım alanına sahip iken bir kısmı daha dar bir alanda yayılış göstermektedir. Familya üyeleri tıbbi ve aromatik özellikte olmaları nedeniyle doğadan kontrolsüz bir şekilde toplanmakta, bu ise özellikle dar yayılış alanına sahip olan türlerin populasyonlarının daha da daralmasına neden olmaktadır. Bu durumun devamı halinde ilerleyen yıllarda özellikle küçük populasyona sahip türlerin yok olma tehlikesi ile karşı karşıya kalacağı öngörülmektedir. Bunun önüne geçebilmek için; tıbbi, endemik ve tehlike altında bulunan türlerin korunması için zaman geçirmeksizin koruma stratejilerinin oluşturulması ve derhal pratiğe aktarılması gerekmektedir.

In situ ve ex situ koruma stratejileri bu anlamda önem kazanmaktadır. Ex situ koruma stratejilerinden biri olan doku kültürü yöntemleri kullanılarak; in vitro üretim prosedürü belirlendikten sonra çok kısa sürede ve çok sayıda bitkinin çoğaltımı sağlanabilmektedir. Doku kültüründe başlangıç materyali eksplant olarak adlandırılır. Doku kültürü çalışmaları için en uygun eksplant kaynağ 1 ise tohumların in vitro çimlendirilmesi ile elde edilen fidelerdir (Mercier ve Kerbauy, 1997).

Çimlenme olayı çoğu çiçekli bitki de yaşama başlangıcının ilk adımıdır. Bu aşama, dinlenme evresindeki tohum tarafından suyun alınımını izleyen embriyonik eksen olan kökün ortaya çıkmasıyla sona ermektedir (Zielinski ve ark., 2006). Nadir ve endemik türlerin koruma çalışmalarında strateji oluşturabilmek için tohum çimlendirmesinin aydınlatılması önemlidir (Lorite ve ark., 2007; Blanca ve ark., 1998; Moreno-Saiz ve ark., 2003).

Çimlenmeyi etkileyen içsel ve dışşal faktörler vardır. Bitki büyüme düzenleyicilerinden bir k1smı (oksin, sitokinin ve gibberellinler) çimlenmeyi teşvik ederken, absisik asidin ise çimlenmeyi engelleyici ektisinin olduğu bilinmektedir (PalavanÜnsal, 1993; Ünyayar, 1995).

Türkiye de Clinopodium cinsi 3'ü endemik olan 16 tür ile temsil edilmektedir (Kuşaksı, 2019). Micromeria dolichonta P.H Davis Uluslararası Doğayı Koruma Birliği (IUCN) tehdit kategorilerine göre çok tehlikede "CR" kategorisindedir (Ekim ve ark., 2000). Son yıllardaki gerçekleştirilen sistematik ve filogenetik çalışmalar ile tür Clinopodium cinsine aktarılmış ve Clinopodium dolichodontum (P.H.Davis) Bräuchler \& Heubl olarak yeniden adlandırılmıştır (Bräuchler ve ark., 2006). Bu türün Türkçe adı ise "Dişli Fesleğen" olarak verilmektedir (Güner ve ark., 2012).

Clinopodium cinsine ait türler tıbbi ve aromatik özelliğe sahiptirler. Bunlardan Clinopodium bolivianum türünün antienflamatuvar (Soumitra ve ark., 2017), Clinopodium macrostemum var. laevigatu 'in DPPH radikalini giderici etkisinin
(Turner, 2008; Villa-Ruano ve ark., 2013) olduğu, $C$. macrostemum var. macrostemum ise antioksidan, karaciğer ve nöron koruyucu etkisininin olduğu bulunmuştur (Perez, 2013). Clinopodium vulgare L. subsp. vulgare 'nin antitümoral (Dzhambazov ve ark., 2002) ve antibakteriyel (Opalchenova ve Obreshkova, 1999; Şener ve ark., 2018) ve antioksidan (Şener ve ark., 2018) özellik gösterdiği saptanmıştır.

Clinopodium dolichodontum türü ise izomenton (\%23), ctspiperiton oksit (\%17), pulegon (\%15), piperiton (\%10) içermektedir (Başer ve ark., 1997). C. dolichodontum toprak üstü kısımları, çiçek dalları, yaprakları, sürgünleri yaygın olarak halk tarafından kullanılmaktadır. Türün çeşitli kısımları safra taşlarına, ağrı kesici olarak, mide-bağırsak hastalıkları için, soğuk algınlığına, gribe, nefes darlığı ve göz rahatsızlıklarında tedavi için kullanılmakta (Öztürk ve Altay, 2017); ayrıca, toprak üstü kısımları kurutulup, bitki çayı olarak tüketilmektedir (Sargın ve Büyükcengiz, 2019).

Öte yandan, günümüze dek türün korunmasına ve çoğaltılmasına yönelik sadece bir çalışma olup, o da türün aksiller çoğaltım yoluyla üretimini içermekte (Emek, 2018a); ancak, şimdiye kadar, türün in vitro koşullarda çimlenmesi ve fide gelişimi ile ilgili olarak yapılmış herhangi bir çalışmaya rastlanılmamıştır.

$\mathrm{Bu}$ çalışmanın amacı, endemik ve tıbbi önem taşıyan ve yok olma tehlikesi olan C. dolichodontum 'un in vitro koşullardaki çimlenme ve fide gelişimi gereksinimlerini belirlemektir.

\section{Materyal ve Metot}

\subsection{Tohum Sterilizasyonu}

Tohumlar sterilize edilmeden önce akan çeşme suyu altında bir saat boyunca yıkanıp, ardından steril laminar kabine alınarak bir dizi işleme tabii tutuldu; sırasıyla \% 50'lik EtOH'de 1 dakika, \% 2.5'lik NaOCl'de (3-4 damla tween-20 içeren) 5 dakika bekletildikten sonra, üç kez 5'er dakika steril distile su ile durulanmıştır.

\subsection{In vitro Çimlenme}

Çimlenme denemeleri, C. dolichodontum tohumlarının çimlenmesi üzerine farklı besin ortamlarının ve gibberellik asidin $\left(\mathrm{GA}_{3}\right)$ etkisini belirlemek için planlanmıştır.

Steril edilen tohumlar 50'şer mL besin ortamı içeren 190 cc'lik kavanozlarda kültüre alınmışlardır. Denemelerde sıv1 ortamlar kullanılmıştır ve tohumlara fiziksel destek sağlayabilmek için bilye ve kağıt köprüler içeren kavanozlar hazırlanmıştır.

\subsection{1. Çimlenme Üzerine In vitro Besin Ortamlarının Etkisi}

Çimlenme üzerine in vitro besin ortamının etkisini belirlemek amaciyla MS (Murashige ve Skoog, 1962), White (WH), (White, 1963) ve B5 (Gamborg ve ark., 1968) ortamları kullanılmıştır. Distile su (DS) ortamı ise kontrol olarak kullanılmıştır. Besin ortamlarının pH'sı, 0.1 molar sodyum hidroksit ve 0.1 molar hidroklorik asit çözeltileri kullanılarak DS ve MS için 5.8'e, White ve B5 ortamları için 5.5'e ayarlanmıştır. Hazırlanan besin ortamları önceden hazırlanmış kavanozlara paylaştırılmış ve kavanozlar $121{ }^{\circ} \mathrm{C}$ 'ta $105 \mathrm{kPa}$ basınç altında 15 dakika boyunca steril edilmiştir.

\subsubsection{Cimlenme Üzerine Giberellik Asidin Etkisi}


Çimlenme üzerine giberellik asit $\left(\mathrm{GA}_{3}\right)$ etkisini belirlemek için farklı konsantrasyonlarda $\mathrm{GA}_{3}\left(0,1,2\right.$ ve $\left.3 \mathrm{mg} \mathrm{L}^{-1}\right)$ içeren distile su (DS) ortamları kullanılmıştır. Gibberellik asit 0.22 $\mu$ m'lik milipore filtre kullanarak steril edilmiştir.

Tüm çimlenme denemeleri kavanoz başına 20 tohum olacak şekilde 3 tekrarlıdır. Tüm denemeler $2 \mathrm{kez}$ tekrar edilmiştir. Kültürler $25 \pm 2{ }^{\circ} \mathrm{C}$ 'ta ve 16 -h 1şık periyodunda tutulmuşlardır.

Radikula çıkışı çimlenme kriteri olarak kabul edilmiş; değerlendirmeler altı haftanın sonunda aşağıda verilen formül ile hesaplanmıştır (ISTA, 1999)

$\%$ Çimlenme $=$ Çimlenen tohumların sayısı $/$ Toplam tohum say1s1 $\times 100$

\subsection{In vitro Fide Gelişimi}

Türün fide gelişimi için uygun besin ortamının belirlenmesi için MS, White ve B5 ortamları kullanılmıştır. Besi ortamları \% 0.8 Agar-Agar (Merck) ile katılaştırılmıştır. Hazırlanan ortamlar $121{ }^{\circ} \mathrm{C}^{\prime}$ ta $105 \mathrm{kPa}$ altında 15 dakika boyunca steril edilmiştir.

Çimlenen tohumlardan elde edilen steril bitkicikler fide gelişimi için MS, B5 ve WH ortamlarına aktarılmışlardır. Kültürler $25 \pm 2{ }^{\circ} \mathrm{C}$ 'ta ve 16 -h 1şık periyodunda tutulmuşlardır.

Bitkicikler her kavanoza iki fide olacak şekilde kültüre alınmış olup, her bir denemede 10 kavanoz kullanılmış ve tüm denemeler üç kez tekrar edilmiştir. Kültürler dört haftalık periyotlarla alt kültür edilmiştir. İkinci alt kültür sonunda fidecikler sürgün sayısı, maksimum sürgün boyu, kök sayısı ve kök boyu dikkate alınarak değerlendirilmiştir.

Araştırmada elde edilen verilerin değerlendirilmesi SPSS 16 programı ile yapılmış; ortalamalar arasındaki farklılıklar Duncan Çoklu Oran Testi $(\mathrm{p}<0.05)$ ile saptanmıştır.

\section{Araştırma Sonuçları ve Tartışma}

\subsection{In vitro Çimlenme}

Tohum sterilizasyonu \%100 oranında steril kültür eldesi ile başarılı olmuştur. In vitro tohum çimlenmesi üzerine besin ortamının etkisini araştırmak amacıyla gerçekleştirilen denemede farklı oranlarda çimlenme elde edilmiştir. Besin ortamı bileşimi çimlenmeyi etkilemiştir. En yüksek çimlenme değeri (\%60) DS 'da, en düşük çimlenme değeri (\% 30) ise B5 ortamında elde edilmiştir (Şekil 1).

Tohum çimlenmesi sırasında mineral madde gereksinimi türden türe değişmektedir (Padilla ve Encina, 2003). C. dolichodontum tohumlarının çimlenebilmesi için mineral madde gereksinimi yoktur. Benzer sonuçların elde edildiği pek çok çalışma bulunmaktadır. Centaurea zeybekii in vitro tohum çimlenmesi üzerine gerçekleştiren bir çalışmada, MS, B5, White ortamları ile vitamin destekli distile su 'nun çimlenme üzerine etkisi araştırılmış ve en yüksek çimlenme değerinin distile suda elde edildiği belirtilmiştir (Kurt ve Erdağ, 2009). Tibbi endemik bir tür olan Nepeta viscida Boiss.' nın in vitro tohum çimlenmesi ve fide gelişimi üzerine gerçekleştirilen bir çalışmada, çimlenme üzerine in vitro besin ortamlarının etkisi araştırılmış ve en yüksek çimlenme değerinin (75\%) $2 \mathrm{mg} \mathrm{L}^{-1} \mathrm{GA}_{3}$ ilaveli DS ortamında elde edildiği belitilmiştir (Emek, 2018b). Benzer şekilde, Erdağ ve ark. (2018) 'nın Nepeta nuda subsp. albiflora 'nın tohum çimlenmesi ile ilgili olarak gerçekleştirdikleri çalışmada da türün çimlenme için besin gereksinimi olmadığ 1 belirtilmiş ve en yüksek çimlenme değeri (\%85) distile su'da elde edilmiştir.

Denemelerde kullanılan in vitro ortamların tuz içerikleri birbirinden farklıdır. MS ortamı yüksek tuz içeriğine sahip bir ortamdır ve genellikle yüksek tuz içerikli besin ortamları çimlenmeyi azaltmaktadır (Bauri ve ark., 2009). Bazı bitkiler için tuzluluk, tohum çimlenmesini olumsuz olarak etkileyen bitki gelişimini geciktiren ve ürün oluşumunu da azaltan bir faktör olarak değerlendirilir (Greenway ve Munns, 1980). Tuzluluk, ya su alınımını engelleyen osmotik potansiyele neden olarak ya da embriyo canlılığı üzerine iyonların toksik etki oluşturarak tohum çimlenmesini olumsuz şekilde etkileyebilir (Lianes ve ark., 2005).

Giberellik asidin çimlenme üzerine etkisinin araştırıldığı çalışmalar sonucunda $\mathrm{GA}_{3}$ ün çimlenme üzerine pozitif etki göstermiş olduğu gözlenmiştir (Şekil 2). Tüm $\mathrm{GA}_{3}$ uygulamalarında çimlenme teşvik edilmiştir. Ancak en yüksek çimlenme oranı ( \% 80) $1 \mathrm{mgL}^{-1} \mathrm{GA}_{3}$ içeren DS ortamında elde edilmiştir.

Giberellik asidin; Labiatae familyası üyelerinin tohum çimlenmesini teşvik ettiği saptanmıştır (Yücel, 1996; Gökçeoğlu ve Sukatar, 1987; Ünal ve ark., 2004; Emek, 2018b; Hilooğlu ve ark., 2016). Giberellinler, çimlenmenin başlaması ve kontrolünde önemli rollerinin yanısıra, dormant tohumlarda absisik asidin etkisini kaldırıp, nişasta ve depo proteinlerinin hidrolizini hızlandırarak çimlenmeyi uyarmakta (Cardemil ve Rainero, 1982); ayrica, tohumlara eksojen olarak uygulanan Gibberellik asidin, $\alpha$-amilaz enzimi etkinliğini arttırmaktadır (Wurzburger ve Lehsem, 1974).

\subsection{In Vitro Fide Gelişimi}

Çimlenme sonrası elde edilen steril bitkicikler; gelişimleri için uygun olan in vitro ortamın belirlenmesi amacıyla MS, B5 ve White ortamlarında kültüre alınmışlardır. Kültür ortamının kimyasal komposizyonu in vitro bitki çoğaltım çalışmalarında önemli rol oynamakta, optimal koşulların dışındaki kültür ortamı türlerde hastalıklara ve doku ölümüne neden olabilmektedir.

İkinci alt kültür sonucunda MS, B5 ve WH ortamlarındaki fideler değerlendirildiğinde en yüksek sürgün sayısı (6.10 0.24$)$, maksimum sürgün boyu $(6.86 \pm 0.81)$, kök sayısı $(6.80 \pm 1.09)$ ve kök boyu (5.41 \pm 0.53$)$ ile fide gelişimi için en uygun ortamın MS olduğu sonucuna varılmıştır (Tablo 1, Şekil 3).

Fideler 2. alt kültür sonucunda değerlendirildiğinde, WH ortamı fide gelişimini olumsuz yönde etkilemiş, bu nedenle fidelerde doku ölümleri ile canlılık kaybı görülmeye başlamıştır. White besi ortamına aktarılan fidelerin \% 60'nın hayatta kaldığı; B5 ve MS ortamınlarında yetiştirilen fidelerin ise \%100 oranında canlılıklarını korudukları gözlenmiştir. Bulgularımız, araştırmalrında deneme materyali olarak Lamiaceae familyasından Dorystoechas hastata (Erdağ ve ark., 2010), Centaurea zeybekii (Kurt ve Erdağ, 2009), Nepeta viscida Boiss. (Emek, 2018b) türlerini kullanan araştırmacıların bulguları ile benzerlik ve uyum içindedir.

Öte yandan, kullanılan besin ortamları mineral içerikleri bakımından birbiriyle karşılaştırıldığında çoktan aza doğru MS, B5 ve WH olduğu bilinmektedir. B5 ortamı MS ortamı ile karşılaştırıldığında MS' e göre daha düşük nitrat ve amonyum içermektedir. Azot, bitkilerin in vitro ve in vivo büyümesine katkıda bulunan ana unsurlardan biridir.Aminoasitlerin, proteinlerin, bazı bitki büyüme düzenleyicileri ve klorofilin yapısına katılmaktadır. MS ortamı toplamda $60.03 \mathrm{mM}$ azot içerirken, B5 ve WH ortamı sırasıyla $27.03 \mathrm{mM}$ ve $3.33 \mathrm{mM}$ azot içermektedir (Bhojwani ve Razdan, 1996). Bu nedenle MS ortamındaki fide gelişimi daha iyi olmakta; WH ortamı ise fide gelişimi için yeterli olmamaktadır. 
İçerdikleri vitamin bakımından bu üç besi ortamı kıyaslandığında, WH ortamı diğer ortamlara göre daha düşük oranda vitamin içermektedir (Bhojwani ve Razdan, 1996). Bitkiler büyüme ve gelişme için vitaminleri sentezlerler (Chawla, 2002). Ancak, in vitro'da büyüyen bitki hücreleri

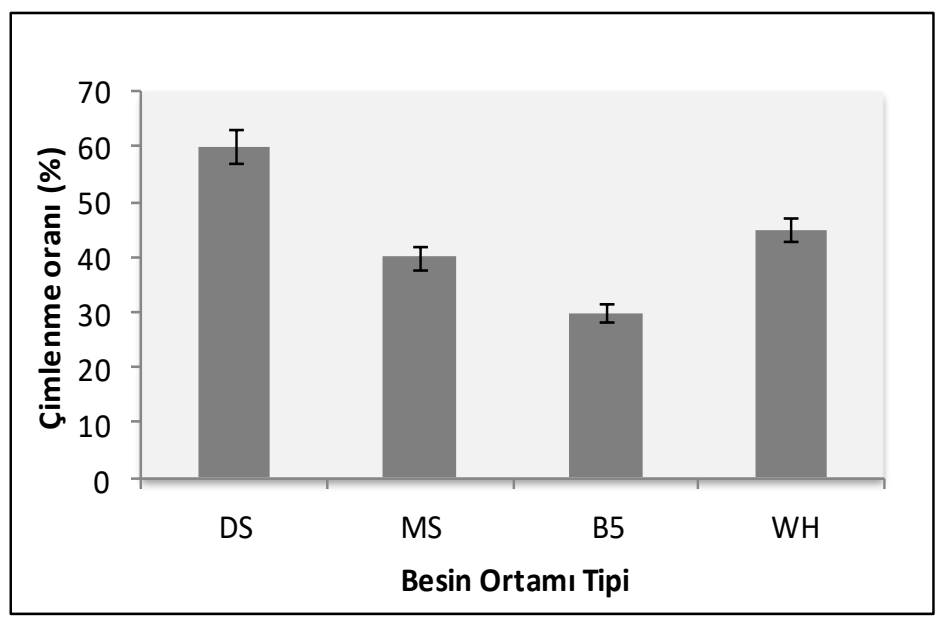

Şekil 1. C. dolichodontum tohumlarının in vitro çimlenmesi üzerine besin ortamlarının etkisi gerekli vitaminleri yalnızca optimal miktarın altında sentezleyebilirler; bu nedenle kültür ortamları büyümeyi arttırmak için vitaminlerle desteklenmelidir (Bhojwani ve Razdan, 1996). WH ortamının fide gelişimi için yetersiz gelmesi düşük besin ve vitamin içermesinden kaynaklanmaktadır.

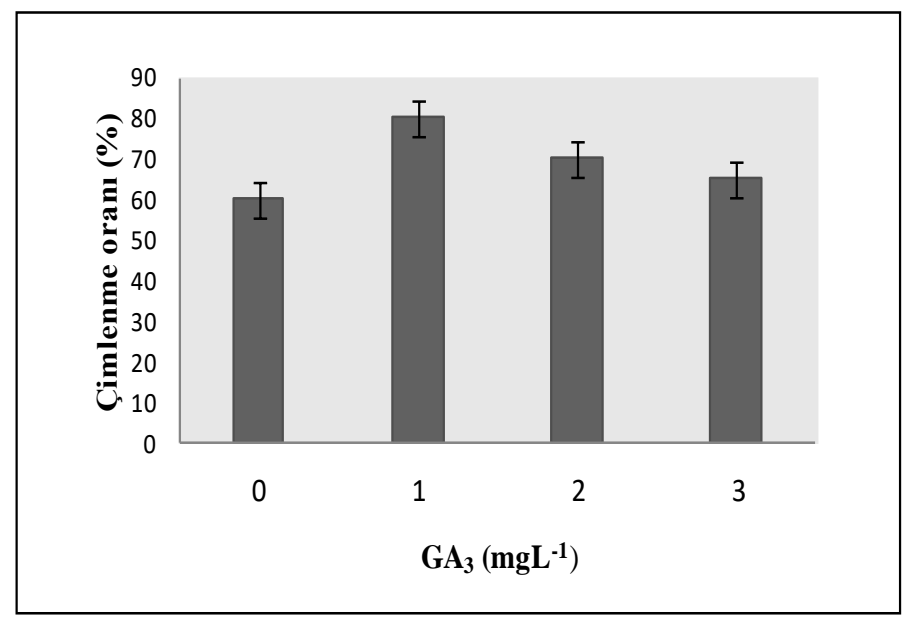

Şekil 2. C. dolichodontum tohumlarının in vitro çimlenmesi üzerine $\mathrm{GA}_{3}$ 'ün etkisi.

Tablo1 . C. dolichodontum'un in vitro fide gelişimi üzerine besin ortamının etkisi

\begin{tabular}{|c|c|c|c|c|c|}
\hline & $\begin{array}{l}\text { Besi } \\
\text { Ortam }\end{array}$ & Sürgün Say1s1 & $\begin{array}{l}\text { Maksimum } \\
\text { Sürgün } \\
\text { Boyu(cm) }\end{array}$ & $\begin{array}{l}\text { Kök Boyu } \\
(\mathrm{cm})\end{array}$ & Kök Say1s1 \\
\hline \multirow{3}{*}{ 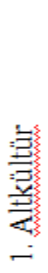 } & MS & $4.19 \pm 0.25 \mathrm{a}$ & $3.70 \pm 0.24 \mathrm{a}$ & $2.98 \pm 0.56 a$ & $2.03 \pm 0.26 \mathrm{a}$ \\
\hline & B5 & $3.30 \pm 0.28 \mathrm{~b}$ & $2.56 \pm 0.20 \mathrm{~b}$ & $2.71 \pm 0.26 \mathrm{a}$ & $1.76 \pm 0.21 \mathrm{a}$ \\
\hline & WH & $2.73 \pm 0.21 \mathrm{~b}$ & $2.00 \pm 0.18 b$ & $2.11 \pm 0.33 \mathrm{a}$ & $1.03 \pm 0.03 b$ \\
\hline \multirow{3}{*}{  } & MS & $6.10 \pm 0.24 \mathrm{a}$ & $6.86 \pm 0.81 \mathrm{a}$ & $5.41 \pm 0.53 \mathrm{a}$ & $6.80 \pm 1.09 \mathrm{a}$ \\
\hline & B5 & $4.26 \pm 0.41 \mathrm{~b}$ & $4.26 \pm 0.57 b$ & $4.31 \pm 0.56 \mathrm{ab}$ & $4.56 \pm 1.14 \mathrm{a}$ \\
\hline & WH & $2.96 \pm 0.25 \mathrm{c}$ & $1.06 \pm 0.21 \mathrm{c}$ & $2.91 \pm 0.34 b$ & $1.30 \pm 0.09 b$ \\
\hline
\end{tabular}

Bir sütunda farklı harfle belirtilen ortalamalar Duncan Çoklu Oran Testine göre $\mathrm{p}<0.05$ hata sınırların içinde istatistiksel olarak farklıdır. Değerlerin tümü ortalama \pm S.H (standart hata şeklinde verilmiştir).

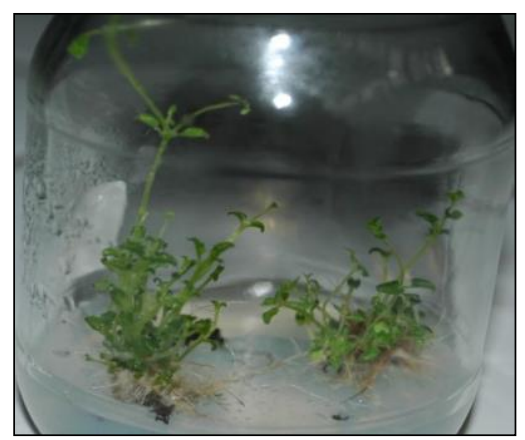




\section{Sonuç}

Clinopodium dolichodontum (P.H.Davis) Bräuchler \& Heubl türü CR kategorisinde yer alan tıbbi öneme sahip endemik bir tür olup; yapılan bu araştırmada türün tohumlarının in vitro ortamdaki çimlenmesi ile fide gelişimi için gereksinim duyulan besin ortamı laboratuvar koşullarında belirlenerek şu bulgulara ulaşılmıştır: Türün tohum çimlenmesi için mineral madde gereksinimi yoktur. Giberellik asit çimelenmeyi teşvik etmiştir ve en yüksek çimlenme değeri (\% 80) $1 \mathrm{mgL}^{-1} \mathrm{GA}_{3}$ ilaveli distile suda elde edilmiştir. Fide gelişimi için en uygun besin ortamının MS ortamı olduğu, ikinci sırayı ise B5 ortamınının takip ettiği söylenebilir. Ancak, WH ortamı düşük besin içeriği nedeniyle fide gelişimi için uygun değildir.

Doğal koşullarda yetişen Clinopodium dolichodontum (P.H.Davis) Bräuchler \&Heubl bitkisi popülasyon ya da popülasyonlarına mekanik veya kimyasal olarak herhangi bir zarar vermeden korumaya almak önemli bir bitki gen kaynağının kullanılabilmesinin, yararlanılmasının ve sürdürülebilmesinin önünü açacak; içerdiği çeşitli tıbbi bileşiklerden etkili bir şekilde yararlanmayı olanaklı kılacak; yapılması düşünülen ya da planlanan çeşitli tarımsal biyoteknolojik veya multidisipliner araştırmalara örnek ve rehber olabilecek niteliktedir.

\section{Teşekkür}

Yazar, araştırmada başlangıç materyali olarak kullanılan tohumların temininden dolayı sayın Prof. Dr. Tuncay Dirmenci 'ye teşekkürü borç bilir.

$\mathrm{Bu}$ çalışmanın bir kısmı 1. Uluslararası Sağlık Bilimleri ve Yaşam Kongresi'nde (IHSCL 2018) sözlü bildiri olarak sunulmuş ve kongre kitapçı̆̆ında özet olarak yayımlanmıştır.

\section{Kaynakça}

Arslan, N., Gürbüz, B., Gümüşçü, A., Sarıhan, E. O., İpek, A., Özcan S, Mirici S ve ark., 2002. Researches on the cultivation of Sternbergia candida Mathew et. Baytop. Proceedings of 14th Meeting of Plant Originated Drugs Eskişehir, Turkey

Başer, K.H.C, Kırımer, N., Duman, H. 1997. Composition of the essential oil of Micromeria dolichodontha P. H. Davis. Flavour and Fragrance Journal 12, 289-291.

Bauri, M.W., Kulkarni, M.G., Street, R.A., Mulaudzi, R.B., Van Staden., J. 2009. Studies on seed germination, seedling growth, and in vitro shoot induction of Aloe ferox Mill., a commercially important species. Hortic. Sci. 44(3),751-756.

Bhojwani, S.S., Razdan, M.K. 1996. Plant Tissue Culture: Theory and Practice. Revised Edition, Elsevier Science, pp. 43, Amsterdam.

Blanca, G., Cueto, M., Martinez-Lirola, M.J., Molero, J. 1998. Threatened vascular flora of Sierra neveda (Southern Spain). Biological Conservation 85, 269-285.

Bräuchler, C., Meimberg, H., Heubl, G.. 2006. New names in old World Clinopodium. - the transfer of the species of Micromeria sect. Pseudomelissa to Clinopodium. Taxon 55, 977-981.

Cardemil, L., Rainero, A. 1982. Changes of Araucaria araucana seed reserves during germination and early seedling. Canadian Journal of Botany 60, 1629-1639.

Celep, F., Dirmenci,T. 2017. Systematic and biogeographic overview of Lamiaceae in Turkey. Naturel Volatiles, Essential Oils 4 (4), 14-27.
Çelikol, D. 2015. Hypericum perforatum bitkisinden elde edilen kantaron yağının yara iyileşmesi üzerine etkilerinin deneysel olarak incelenmesi. Doktora tezi, Cumhuriyet Üniversitesi, Ağız Diş ve Çene Cerrahisi Anabilim Dalı, Sivas, 196s.

Chawla, H.S. 2002. Introduction to Plant Biotechnology Second Revision Edition Science Publishers Inc., p. 750 Enfield, New Hampshire.

Dzhambazov, B., Daskalova, S., Monteva, A., Popov, N., 2002. In vitro screening for antitumour activity of Clinopodium vulgare L. (Lamiaceae) extracts. Biological and Pharmaceutical Bulletin Journal 25, 499- 504.

Ekim, T., Koyuncu, M., Vural, M., Duman, H., Aytaç, Z., Adıgüzel, N. 2000. Türkiye Bitkileri Kırmızı Kitabı (Red Data Book of Turkish Plants), Pteridophyta and Spermatophyta. Türkiye Tabiatını Koruma Derneği, Ankara.

Emek, Y. 2018a. Micromeria dolichodontha P.H. Davis 'nın in vitro aksiller sürgün yoluyla çoğaltımı. Avrupa Bilim ve Teknolojisi Dergisi 14, 337-342.

Emek, Y. 2018b. Researches on in vitro germination and seedling development of medicinal endemic Nepeta viscida Boiss. belonging Lamiaceae family. Fresenius Environ. Bull. 27, 8119-8127.

Erdağ, B., Emek, Y. Kurt, S. 2010. Clonal propagation of Dorystoechas hastata via axillary shoot proliferation. Turk. J. Bot. 34, 233-240.

Erdağ, B., Emek, Y., Kuzu, İ., Bağdatlı, M.N. 2018. Axillary shoot proliferation from aseptic seedlings of Nepeta nuda subsp. albiflora. J. Med. Plant Stud. 6, 34-37.

Ertan, A., Azcan, N., Demirci, B., Başer, K.H.C. 2001. Fatty acid composition of Sideritis species. Chemistry of Natural Compounds 37(4), 301-303.

Gamborg, O.L., Miller, R.A., Ojima, K. 1968. Nutrition requirements of suspension cultures of soybean root cells. Exp. Cell Res 50, 151-159.

Gökçeoğlu, M., Sukatar, A. 1987. Preliminary experiments on germination conditions of Eranthis hyemalis seeds. In: Herbal Drugs Raw Materials Meeting Proceedings Book, Ankara, 154-157.

Greenway, H., Munns, R. 1980. Mechanisms of salt tolerance in non-halophytes. Annual Review of Plant Physiology 31, 149190.

Güner, A., Özhatay, N., Ekim, T., Başer, C. 2000. "Flora of Turkey and the East Aegean Islands (Supplement 2)" Vol. 11. University Press, Edinburgh.

Güner, A., Aslan, S., Ekim, T., Vural, M., Babaç, M.T. 2012. Türkiye bitkileri listesi (Damarlı Bitkiler). Nezahat Gökyiğit Botanik Bahçesi ve Flora Araştırmaları Derneği Yayını, İstanbul.

Hilooğlu, M., Yücel, E., Kandemir, A. Sözen, E. 2016. Endemik Teucrium leucophyllum (Lamiaceae) tohumlarında in vitro çimlendirme çalışmaları. Sinop Uni J. Nat. Sci 1(1), 53-61.

ISTA. 1999. International rules for seed testing. Seed Science and Technology 21, 288 pp.

Kurt S, Erdağ, B. 2009. In vitro germination and axillary shoot propagation of Centaurea zeybekii. Biologia-Section Botany 64(1), 97-101.

Kuşaksız, G. 2019. Rare and endemic taxa of Lamiceae in Turkey and their threat categories. Journal of Scientific Perspectives 3 (1), 69-84.

Lianes, A., Reinoso, H., Luna. V. 2005. Germination and early growth of Prosopis strombulifera seedlings in different saline 
solutions. World Journal of Agricultural Sciences 1(2), 120128.

Lorite, J., Ruiz-Girela, M., Castro, J. 2007. Patterns of seed germination in Mediterranean mountains: study on 37 endemic or rare species from Sierra Nevada, SE Spain. Candollea 62, 5-16.

Mercier, H. Kerbauy, G.B. 1997. Micropropagation of ornamental bromeliads (Bromeliaceae). Biotechnol. Agric. For. 40, 4357.

Morene-Saiz, J.C., Dominguez, F., Sainez-Ollero, H. 2003. Recent progress in conservation of threatened Spanish vascular flora: A critical review. Biological Conservation 113, 419-431.

Murashige, T., Skoog, F. 1962. A revised medium for rapid growth and bioassays with tobacco tissue cultures. Plant Physiology 15, 473-497.

Opalchenova, G., Obreshkova, D. 1999. Antibacterial action of extracts of Clinopodium vulgare L. curative plant. Drug Development and Industrial Pharmacy 25, 323-328.

Öztürk, M., Altay, V., Gücel, S., Altundağ, E. 2017. Plant diversity of the Drylands in Southeast Anatolia-Turkey: role in human health and food security. In: Ansari, A.A., Gill, S.S. (Eds.), Plant Biodiversity: Monitoring, Assessment and Conservation. CABI, Wallingford, pp. 83-124.

Padilla, I.M.G., Encina, C.L. 2003. In vitro germination of cherimoya (Annona cherimola Mill.) seeds. Hortic. Sci. 97, 219-227.

Palavan-Ünsal, N., 1993. Bitki Büyüme Maddeleri. İst. Üniv. Basımevi ve Film Merkezi, Üniversite Yayın No: 3677, İstanbul.

Perez, G.R.M. 2013. Antihepatotoxic, nephroprotective, and antioxidant activities of phenolic compounds from Satureja macrostema leaves against carbon tetrachloride induced hepatic damage in mice. Medicinal Chemistry Research 22, 1846-1855.

Sargın, S.A., Büyükcengiz, M. 2019. Plants used in ethnomedicinal practices in Gulnar district of Mersin, Turkey. J. Herb. Med. 15, 1-18.

Soumitra, M., Witchuda, K., Silvia, Z., Corine, S., Eduardo, G., Claes-Goran, O., Annelie, B. 2017. Extract of Clinopodium bolivianum protects against $E$. coli invasion of uroepithelial cells. Journal of Ethnopharmacology 198, 214-220.

Şener, S.Ö., Korkmaz, S., Akkaya, Ş., Badem, M., Aliyazıcıoğlu, R., Özgen, U., Karaoğlu, Ş.A. 2018. Clinopodium vulgare L. subsp. vulgare ekstresinin antioksidan, antimikrobial, tirozinaz inhibitor aktiviteleri ve RP-HPLC ile fenolik bileşiklerinin araştırılması. GÜFBED/GUSTIJ (2018) 8 (2), 230-238.

Tosun, A., Süntar, İ., Keleş, H., Kiremit, H., Asakawa, Y., Akkol, E. 2016. Wound healing potential of selected liverworts growing in Turkey. Turkish Journal of Pharmaceutical Sciences 13, 3, 285-291.

Turner, B. L. 2008. Taxonomic status of Clinopodium macrostemum (Lamiaceae). Phytologia 90, 411-413.

Ünal, O., Gökçeoğlu, M., Topcuoğlu, F.S. 2004. Investigations on seed germination and propagation of Origanum species endemic for Antalya. Journal of Agricultural Faculty of Akdeniz University 17(2), 135-147.

Ünyayar, S., 1995. Phanerochaete chrysosporium ME446'da kültür periyoduna bağlı olarak indol-3-asetik asit (IAA), gibberellik asit $\left(\mathrm{GA}_{3}\right)$, absisik asit (ABA) ve zeatin üretimi ve biyolojik aktivitelerinin tayini. İnönü Üniv. Fen Bil. Enst. Doktora Tezi, p 163.
Villa-Ruano, N., Pacheco-Hernandez, Y., Zurita- Vasquez, G., Betancourt-Jiménez, M.B., CruzDuran, R., Duque-Bautista, H. 2013. Antilipase and antioxidant properties of 30 medicinal plants used in Oaxaca México. Biological Research 46, 153-160.

White P. 1963. The cultivation of animal and plant cells, Ronald Press, New York.

Wurzburger, J., Leshem, Y. 1974. The role of gibberellin and the hulls in the control of germination in Aegilos kotshyi Caryopses. Canadian Journal of Botany 52, 1597-1601.

Yücel, E. 1996. A research on seed germina-tion characteristics on Sideritis germanicopoli-tana Bornm. subsp. germanicopolina and Sideritis germanicopolitana Bornm. subsp. viridis Hausskn ex Bornm. Faculty of Science Journal of Anadolu University 2, 65-73.

Zielinski, H., Frias, J., Piskula, M.K., Kozlowska, H. 2006. The effect of germination process on the superoxide dismutaselike activity and thiamine, riboflavin and mineral contents of rape seeds. Food Chemistry 99, 516-520. 